\title{
Aural Abcesses in Eastern Box Turtles
}

\author{
Cheryl Hoggard, DVM, AND \\ Melody McFarland, BS \\ Piedmont Wildlife Center \\ Durham, North Carolina
}

\section{INTRODUCTION}

Piedmont Wildlife Center (PWC) is currently in its second year of existence and has received more than 200 Eastern box turtles, Terrapene carolina carolina. Most of these animals are found after being hit by automobiles or lawnmowers. There are also a significant number that are found lethargic and unable to retract their heads due to large swellings on the head. Experienced wildlife rehabilitators immediately recognize this as an aural (ear) abscess, a relatively common affliction of box turtles.

A study conducted at North Carolina State University (NCS) College of Veterinary Medicine, examined aerobic bacterial isolates from 23 injured or sick free-ranging turtles brought to NCS for care prior to 2003. The NCS admissions and study occurred prior to the existence of PWC. Multiple microbial agents were cultured, which were generally found to be opportunistic Gram-negative bacteria. Of the 23 cultures obtained, the most commonly isolated organisms were Proteus vulgaris $(\mathrm{N}=5)$, Escherichia coli $(\mathrm{N}=5)$, and Aeromonas hydrophila (N=5) (Willer et al 2003). The intention of this paper is to provide an overview of this condition and the common bacteria associated with aural abscesses, and to supply a general understanding of how this condition relates to the anatomy of the ear. PWC is continuing the study begun at

Dr. Hoggard is staff veterinarian and hospital director for Piedmont Wildlife Center in Durham, NC. She holds a BA from East Carolina University and a DVM from NC State University. Dr. Hoggard went to veterinary school after being in the work force intending to work exclusively with wildlife upon graduation.

Ms. MacFarland holds a BS in biology from Millersville University in PA and is a research scientist with bioMerieux of Durham, NC, in the microbiology exploratory research department. She is also a volunteer rehabilitator with Piedmont Wildlife Center and formerly served on the board of the organization.

NCS with turtle aural cultures in an effort to better understand the possible causes of the abscesses. The hope is to eventually discern why wild turtles develop these abscesses and methods to decrease the incidence.

\section{How the abscesses affect anatomical struc-} tures. It is necessary to know the basic anatomy of a turtle's ear in order to understand how aural abscesses develop. Most reptiles' ears are very similar to the mammalian ear internally, but turtles lack an external ear. The tympanic membrane, tympanic cavity (a blind-end sac in turtles), the ossicle (columella), extracollumela, and the cochlear window make up the middle ear. The extracollumella inserts into the cochlear window. The part of the ear that is visible on the exterior of the head is the tympanic membrane. The tympanic membrane transmits sound waves to the columella and extracollumella; these structures then transfer that information to the inner ear. The vibrations that are created by the bone (columella) of the middle ear are transferred to the fluid of the inner ear, which in turn causes the cells of the cochlea to move. This movement is transmitted to the brain via the vestibulocochlear nerve (Murray 1996) (Figure 1).

The eustacian tubes provide direct communication between the middle ear and the oropharynx (oral cavity). The opening of each eustacian tube into the oral cavity is adjacent to the choana (internal nares). Pathogens may ascend through this opening into the middle ear (Figure 2). This generally does not occur in healthy animals; however, due to a number of factors, including prolonged exposure to suboptimal temperature, poor nutritional plane, and poor husbandry practices, a turtle can become immunocompromised and opportunistic infection into the middle ear can ensue.

Once certain pathogens enter the middle ear via the eustacian tube, cells lining those structures begin 


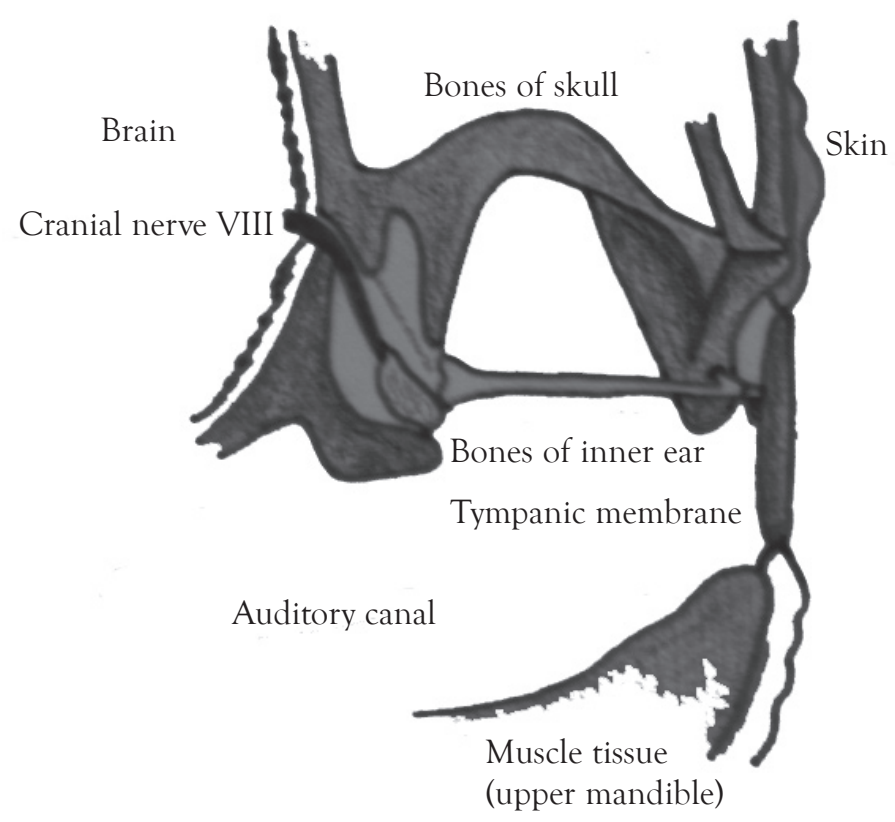

Figure 1. Anatomical structures of the turtle ear (adapted from Murray 1996). ears was recorded. Any concurrent medical or surgical issues were addressed before treating the abscess(es). Out of the 200 plus PWC eastern box turtle admissions, five had aural abscesses and two of these were cultured as outlined below.

Sampling. Because the interior of the caseous material is avascular (lacking blood supply), systemic antibiotic administration alone will not alleviate the problem. Therefore, aural abscesses must be excised surgically. An assistant restrains the turtle for the surgical procedure by carefully extending the neck and holding the head. To prevent further injury to the ears or injury to the eyes of the turtle, the assistant holds the extended head with the thumb and index fingers placed behind both mandibles to prevent the turtle from retracting its head. Care must be taken not to exert excess pressure both when restraining the turtle and when expressing the abscess as one can cause additional damage to both the ears and tissues of the eye.

The tympanum was first desensitized with no more than $10 \mathrm{mg} / \mathrm{kg}$ of one percent $(10 \mathrm{mg} / \mathrm{ml})$ lidocaine (Abbott Laboratories, Abbott Park, IL) injected ventral to midline of the abscess. An incision of $0.5 \mathrm{~cm}$ length was made ventral to midline of the tympanum (depending on the size of the abscess), using a number 11 surgical blade. The abscess contents were gently expressed manually onto a prepared sterile field. In two turtles samples were aseptically taken using a sterile swab to collect material from the removed caseous mass and a second sterile swab was gently inserted under the tympanum and into the now evacuated ear canal to collect additional material for a second culture sample. Following the mass removal (and sample collection in the two aforementioned animals), the affected ear was flushed well with normal saline using an 18-gauge angiocatheter attached to a $10-\mathrm{ml}$ luer-lock syringe. Flushing was done to remove any small abscess particles remaining, and to clean the area. While flushing, the turtle wass held at a 45-degree angle (head pointing towards the table) in order to prevent aspiration of flushing liquids. The oral cavity was checked for exudative contents and swabbed clean. Sterile triple antibiotic ophthalmic ointment was applied inside the ear via a 24-gauge angiocatheter attached to a 1-ml syringe (approximately $0.05 \mathrm{ml}$ per ear). 


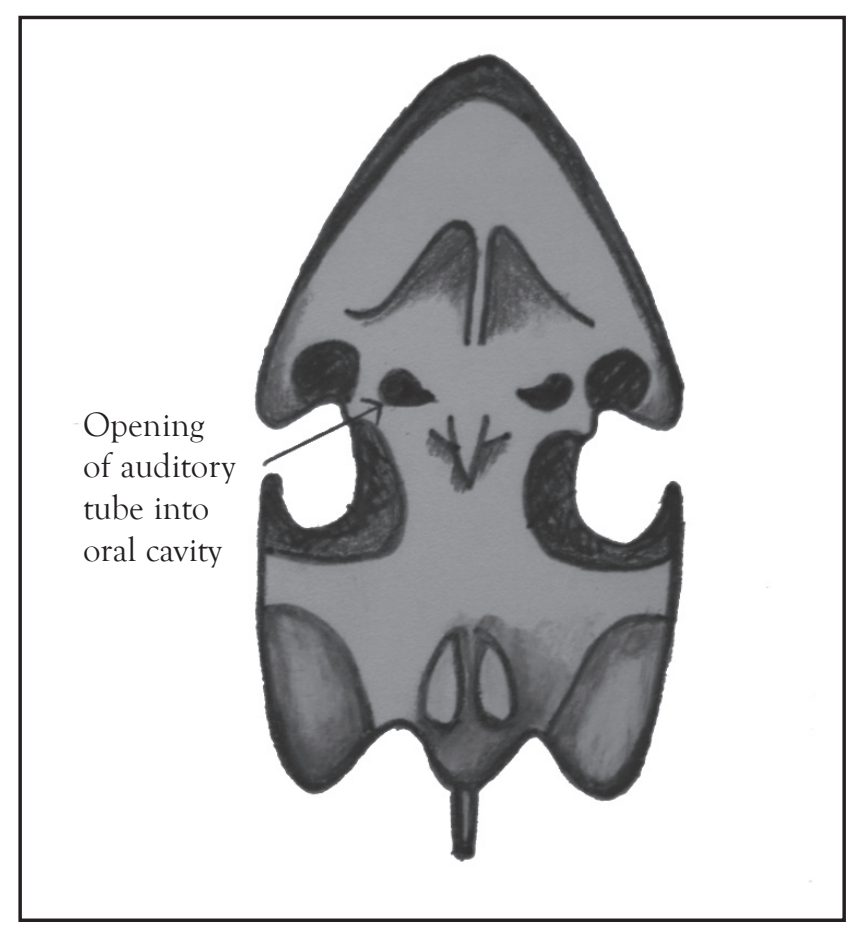

Figure 2. View of upper mandible (hard palate).

Culture and Identification. The sample collection swabs were broken off into a tube of tryptic soy broth and incubated at $37^{\circ} \mathrm{C}$ overnight for enumeration. Enumerated broth was subcultured to blood agar (BAP) and MacConkey's agar for isolation. Plates were incubated overnight at $37^{\circ} \mathrm{C}$. All isolates were gram stained and subcultured again to BAP. After incubating at $37^{\circ} \mathrm{C}$ for 18 hours, all isolates were identified on the Vitek 2 Microbial Identification System (bioMerieux, Marcy L'Etoile, France) for species identification (additional information < http:// www.biomerieux-usa.com/clinical/microbiology/ vitek $2 />$ ). Isolates were identified by means of the ID-GNB and ID-GPC test cards for identification.

\section{RESULTS}

The following organisms were found on all cultures from both animals (Table 1):

Treatment. Providing supportive care via good nutrition, fresh clean water, and optimum temperature ranges was imperative to reduce the recovery time. Additionally, the ears were flushed and triple antibiotic ophthalmic ointment applied once daily for three to four days post operatively. It was normal to see swelling for up to one week once the abscess had been removed, but the swelling would gradually decrease. The incision was allowed to heal by second intention, which enabled flushing and further removal of caseous material if needed. Care was taken to avoid trauma to the patient's eyes when treating the area. Applying too much pressure while extending the neck can also be detrimental. Systemic antibiotics were not necessary unless there was a concurrent infection or unless the abscess recurred.

\section{Discussion}

As rehabilitators, we often receive calls about wildlife that are rescued from poor living conditions in the hands of the public, as was the case with one of the turtles presented to PWC. Because poor husbandry practices contribute to aural abscess formation in turtles, it is important to obtain a detailed a history. Bacteria grow well in an unsanitary cage or dirty water, an unfortunate occurrence when the public holds wildlife, and chronic exposure to these conditions could be the culprit. It follows that if poor husbandry is the cause, the nutritional plane may also be suboptimal for the animal, resulting in a decreased vitamin A intake. It is well documented that vitamin A deficiency in turtles can affect the epithelial lining of the middle ear and auditory tube (Tangredi 1997). We can assume that the turtle's temperature requirements were likely not being met which would negatively impact the ability to absorb food nutrients properly, even if a balanced diet were offered.

What about the wild-caught turtles presenting with aural abscesses? Two of the turtles received at PWC were found at the same gardening center. Remaining turtle admissions had been found by the roadside at different locations. One that presented dead on arrival suffered from concurrent severe head and shell trauma. Only one had a previous history of chronic poor husbandry conditions. There are several hypotheses surrounding the question of aural abscesses in wild turtles. The most accepted is

Table 1. The following organisms were found on all cultures from both animals.

\begin{tabular}{|l|c|l|}
\hline Species & T-index & Confidence level \\
\hline Citrobacter brakii & 0.95 & Excellent Identification \\
\hline Enterobacter cloacae & 0.87 & Excellent Identification \\
\hline Enterococcus faecalis & 0.95 & Excellent Identification \\
\hline Escherichia coli & 1.00 & Excellent Identification \\
\hline Klebsiella oxytoca & 0.85 & Excellent Identification \\
\hline Proteus vulgaris & 0.73 & Very Good Identification \\
\hline Proteus mirabilis & 0.89 & Excellent Identification \\
\hline Serratia marcescens & 0.89 & Excellent Identification \\
\hline
\end{tabular}




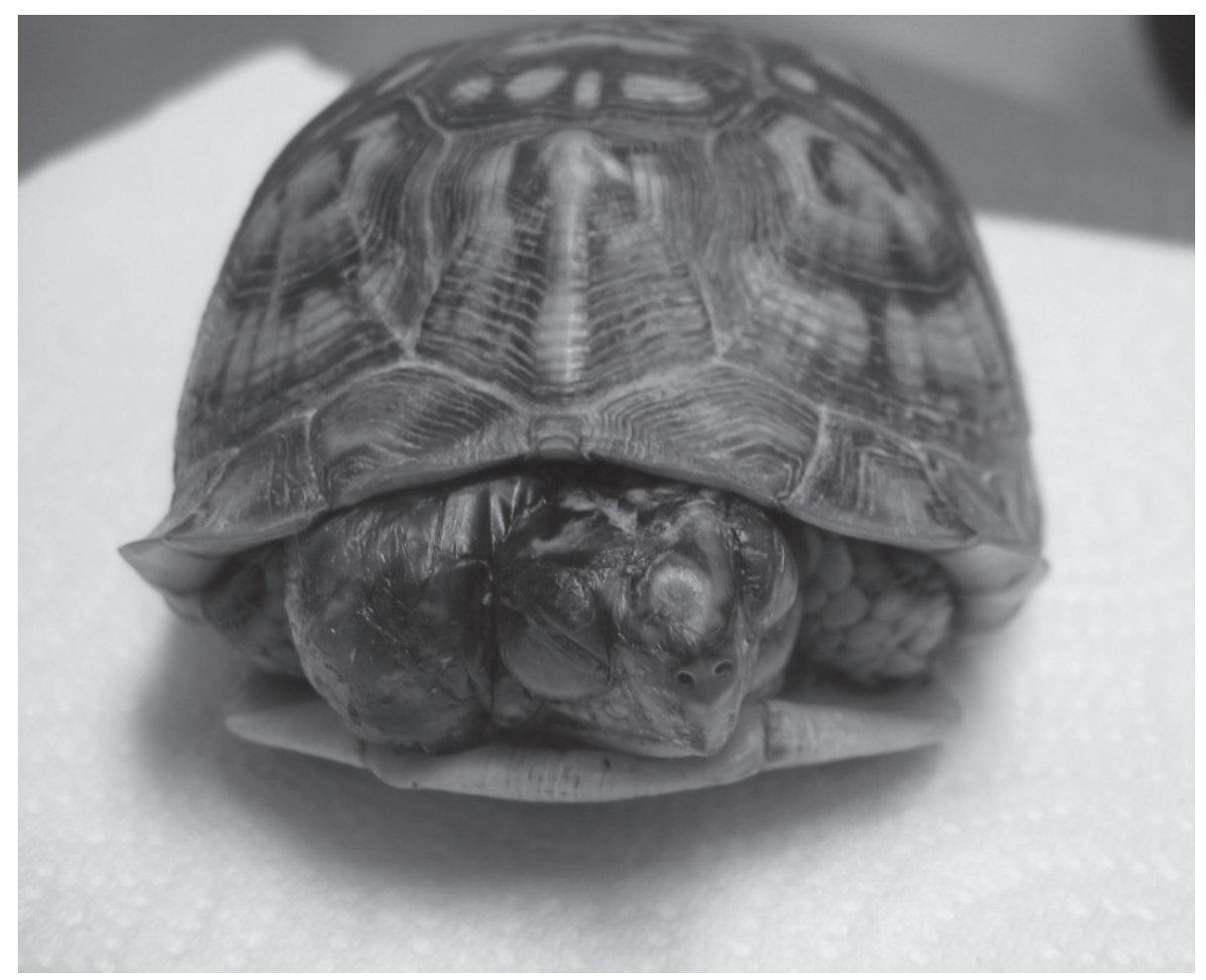

Figure 3. Eastern box turtle (Terrapene carolina carolina) showing head and ear membrane distention on right side as the result of an aural abscess.



Figure 4. Point of incision prior to draining abscess.

that aural abscesses in free-ranging box turtles are caused by hypovitaminosis A, secondary to organochlorine compound toxicity (Holladay et al 2001). Organochlorine compounds, typically found in pesticides and fungicides, have not been in use in the US for many years, due to their negative environmental impact. In the US, the Environmental Protection
Agency (EPA) banned the use of these chemicals in the 1970s and 1980s; however, they continue to be manufactured in the US and used by countries outside the US (additional information < http://www. cdc.gov/exposurereport/2nd/ pdf/organochlorine_all.pdf $>$ ). Organochlorine compounds enter the environment via disposal of contaminated wastes from landfills, emissions from waste incinerators, and releases from manufacturing plants that still produce these chemicals, and may persist in the environment for many years. The bacterial culture results from the turtles admitted to the PWC are comparable to those in the study of NCS with the exception of Aeromonas hydrophila that was not cultured from the PWC turtles. Preliminary findings indicate that E. coli and Proteus vulgaris were common culture growths of both studies. Similarities could be expected as the turtles sampled were from the same three county geographic area of north central North Carolina.

In order to fully understand why aural abscesses occur in free-ranging animals, more data must be compiled. Ensuring documentation of the exact location where the animal was found is the first step. In addition, compilation and comparison of data gathered nationwide will help provide clues as to why this condition occurs in the first place, which will then lead to methods of reduction or even prevention.

\section{LITERATURE CITED}

Holladay, S. D., J. C. Wolf, S. A. Smith, D. E. Jones, and J. L. Robertson. 2001. Aural abscesses in wild-caught box turtles (Terapene carolina): possible role of organochlorine-induced hypovitaminosis A. In Ecotoxicol Environmental Safety. January. 48(1):99-106. 
Murray, M. J. 1996. Aural abcesses. Pp. 349-351 in Reptile Medicine and Surgery (D. R. Mader ed.). W. B. Saunders Co: Philadelphia, PA.

Tangredi, B. P., and R. H. Evans. 1997. Organochlorine pesticides associated with ocular, nasal, or otic infection in the eastern box turtle (Terrapene carolina carolina). Journal of Zoo Wildlife Medicine. 1:97-100.

Willer, C. J., G. G. Lewbart, and C. Lemons. 2003. Aural abscesses in wild Eastern box turtles Terrapene carolina carolina, from North Carolina: aerobic bacterial isolates and distribution of lesions. Journal of Herpetological Medicine and Surgery. 13(2):4-9.

\section{RECOMMENDED \\ READING}

Brown, J. D., J. M. Richards, J. Robertson, S. Holladay, and J. M. Sleeman. 2004. Pathology of aural abscesses in free-living Eastern box turtles (Terrapene carolina carolina). Journal of Wildlife Diseases. 4:704-712.

Brown, J. D., J. M. Sleeman, and F. Elvinger. 2003. Epidemiologic determinants of aural abscessation in free-living eastern box turtles (Terrapene carolina) in Virginia. Journal of Wildlife Diseases. 4:919-921.

Dodd, C. K., Jr. 2001. North American Box Turtles, a Natural History. University of Oklahoma Press: Norman, OK.

Funke, G., P. Funke-Kissling. 2004. Evaluation of the new VITEK 2 card for identification of clinically relevant gram-negative rods. Journal of Clinical Microbiology. 9:4067-4071.

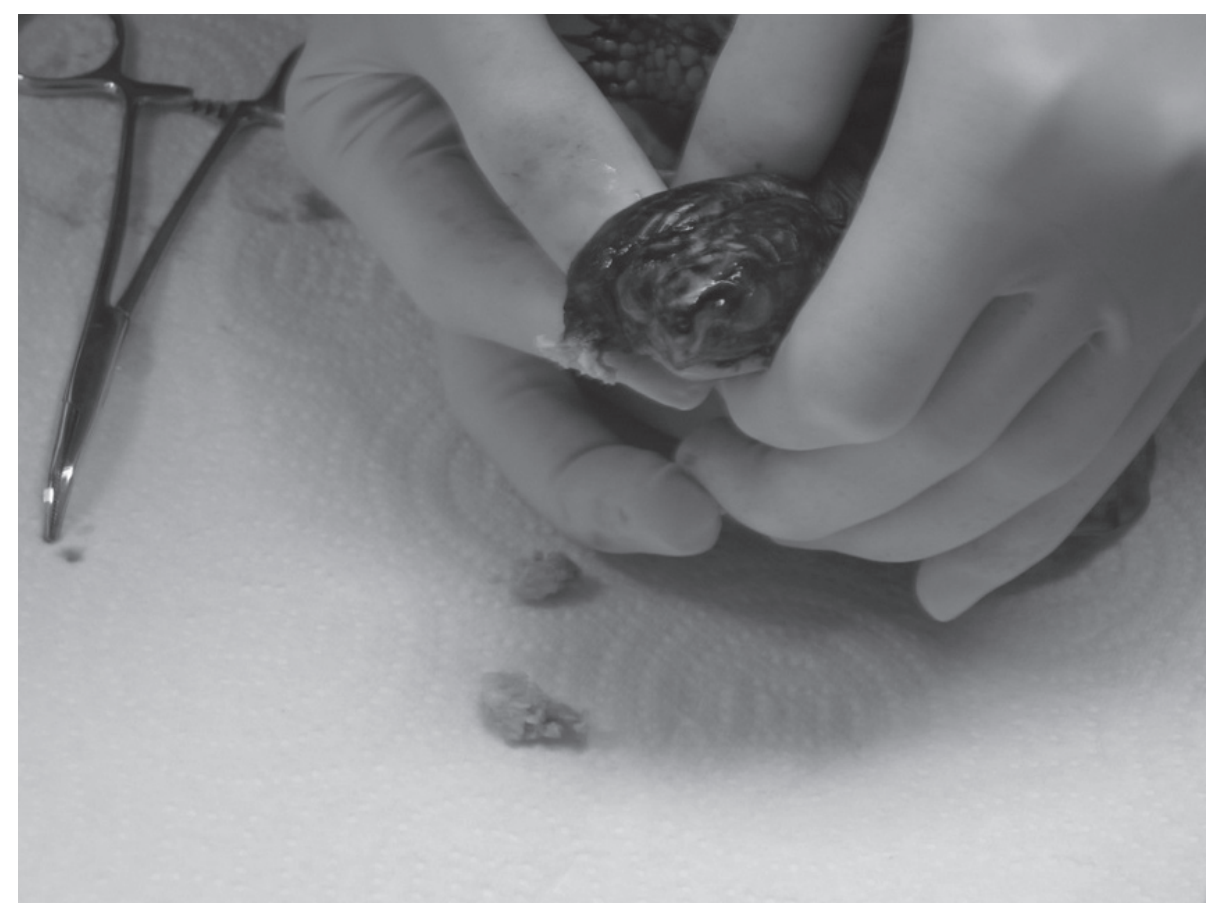

Figure 5. Correct restraint of turtle head while removing aural abscess. Note abscess material removed from ear canal lying on sterile field.

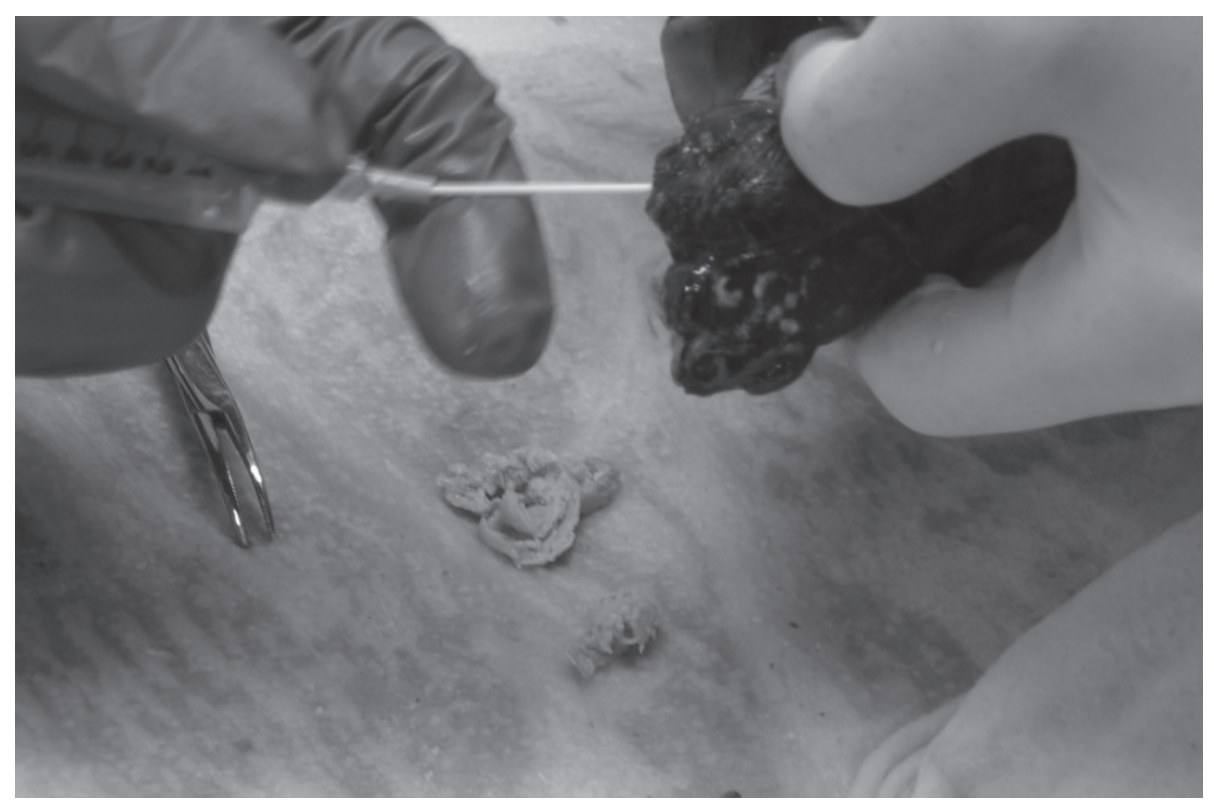

Figure 6. Sterile swab collection for culture and sensitivity testing.

Murray, P. R. (editor in chief). 2003. Manual of Clinical Microbiology 8th ed. ASM Press: Washington, DC. (N⿴囗大) 